\title{
Painful Plantar Lesions: An Unusual Presentation for Rheumatoid Nodules
}

\author{
Pablo Del Barrio-Díaz, $M D^{7}$, Sergio González, $M D^{2}$, and Cristián Vera-Kellet, $M D^{1,3}$ \\ ${ }^{1}$ Facultad de Medicina, Department of Dermatology, Pontificia Universidad Católica de Chile, Santiago, Chile; ${ }^{2}$ Facultad de Medicina, \\ Department of Pathology, Pontificia Universidad Católica de Chile, Santiago, Chile; ${ }^{3}$ Facultad de Medicina, Department of Dermatology, \\ Connective Tissue Diseases Unit, Pontificia Universidad Católica de Chile, Santiago, Chile.
}

KEY WORDS: rheumatoid nodules; rheumatoid arthritis; plantar; nodule; painful.

J Gen Intern Med 32(8):955-6

DOI: $10.1007 / \mathrm{s} 11606-017-4031-0$

(C) Society of General Internal Medicine 2017

A 59-year-old man with rheumatoid arthritis on long-term methotrexate presented with 6 months of multiple painful lesions on his heels that impaired his gait. He denied any trauma to his foot or new medications. Physical examination revealed multiple painful papules and nodules on his heels (Fig.1). A skin biopsy of a nodule showed diffuse interstitial and granulomatous infiltration throughout the dermis, with a central area of necrosis surrounded by palisading epithelioid macrophages (Fig.2), findings consistent with rheumatoid nodules (RN).

He received infliximab and direct injection of intralesional betamethasone. After 6 months of treatment, there was a little improvement, although no new lesions developed.

RN typically appears on extensor surfaces and areas of pressure or repetitive trauma, particularly adjacent to the olecranon and the dorsal aspect of the hand. ${ }^{1}$ Occurrence in the feet is rare, and only sparsely reported in the literature. ${ }^{2}$ Asymptomatic lesions do not require treatment unless they become ulcerated or infected or limit mobility. ${ }^{3}$ Clinicians should be aware of this presentation and differentiate it from conditions with simi-

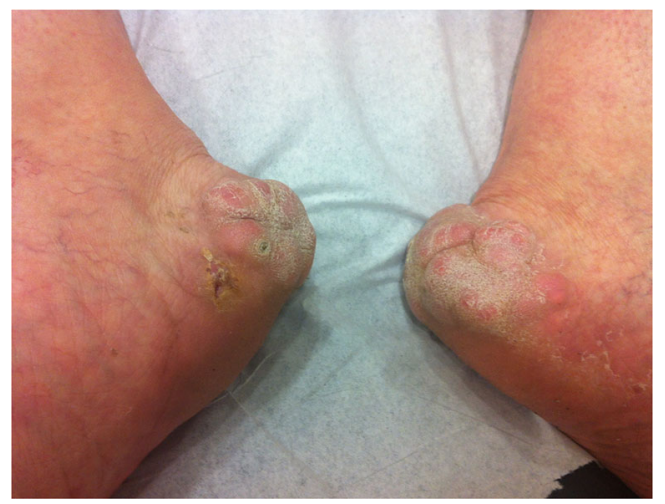

Figure 1 Nodules on the heels.

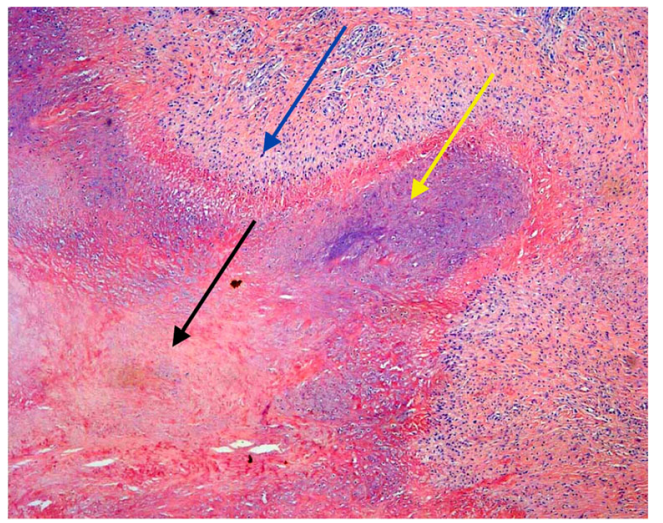

Figure 2 Granuloma with a central area of necrosis (black arrow) surrounded by palisading epithelioid macrophages (yellow arrow) enclosed by granulation tissue (blue arrow). 
lar appearance including fibromas caused by chronic trauma from shoes, subcutaneous granuloma annulare. and sarcoidosis.

Corresponding Author: Cristián Vera-Kellet, MD; Facultad de Medicina, Department of DermatologyPontificia Universidad Católica de Chile, Santiago, Chile (e-mail: cvera@med.puc.cl).

\section{Compliance with Ethical Standards:}

Conflict of Interest: The authors declare that they do not have a conflict of interest.

\section{REFERENCES}

1. Tilstra JS, Lienesch DW. Rheumatoid Nodules. Dermatol Clin. 2015;33(3):361-71.

2. McMurrich W, Thomson C, McKay ND, McRorie E, Salter D, McKinley J. Soft tissue swellings in the foot: rheumatoid nodulosis. Foot (Edinb). 2014;24(1):37-41.

3. Gale M, Gilbert E, Blumenthal D. Isolated rheumatoid nodules: a diagnostic dilemma. Case Rep Med. 2015;2015:352352. 